\title{
Potential screening strategies for early prediction of pre-eclampsia
}

\author{
Hymavathi K., Sandhya Rani Davuluru, Sameera Shaik*, Sahithi Kaviti
}

Department of Obstetrics and Gynecology, Narayana Medical College and Hospital, Nellore, Andhra Pradesh, India

Received: 15 December 2020

Revised: 02 March 2021

Accepted: 03 March 2021

\author{
*Correspondence: \\ Dr. Sameera Shaik, \\ E-mail: sameera153007@gmail.com
}

Copyright: (c) the author(s), publisher and licensee Medip Academy. This is an open-access article distributed under the terms of the Creative Commons Attribution Non-Commercial License, which permits unrestricted non-commercial use, distribution, and reproduction in any medium, provided the original work is properly cited.

\begin{abstract}
Background: This study was conducted to evaluate the efficacy of different biochemical and biophysical markers in the early weeks of gestation as screening tools for early prediction of preeclampsia.

Methods: This hospital-based prospective observational study conducted on 52 pregnant women, at less than 13 weeks of gestation were recruited. Maternal serum inhibin A and USG uterine artery PI levels were analyzed among the pregnant women who subsequently developed PE and compare with those who did not develop PE. Methods used for the detection of markers were: chemiluminescence immunoassay (CLIA) for serum inhibin A levels, and uterine artery Doppler velocimetry was done by PHILIPS HD11XE transabdominal ultrasound machine using a 4-6 MHz probe with the same sonographer.

Results: The present study revealed a significant rise of inhibin A in preeclamptic women when compared to normotensive women $(\mathrm{p}<0.0001)$. The mean levels of $1^{\text {st }}$ and $2^{\text {nd }}$ trimester uterine artery PI significantly high in women who subsequently developed PE when compared to those who did not develop preeclampsia $(\mathrm{p}<0.0001)$. Study results showed a strong association between gestational age at delivery and neonatal outcome (neonatal birth weight and APGAR) with preeclampsia. The maternal serum inhibin A, and uterine artery PI found to have good sensitivity and specificity for early prediction of PE.

Conclusions: Study concluded that the women who are prone to develop PE subsequently, had high levels of MAP, UAPI, inhibin A. In our setting, MAP, UAPI, inhibin A, appeared to be better screening modalities. Combination of the biochemical markers with the biophysical markers, demographic characteristics, and other novel markers will establish the effective screening models for early prediction of PE. Early identification of high-risk cases will offer an opportunity for prophylactic therapy, such as Low- dose Aspirin in selected groups of high-risk women screened in the first trimester, thus improving the maternal and perinatal outcome.
\end{abstract}

Keywords: Antioxidants, Colour Doppler ultrasonography, Pregnancy induced hypertension

\section{INTRODUCTION}

Preeclampsia (PE) affects $2 \%$ of pregnancies, is a major cause of maternal and perinatal morbidity and mortality. In India, the prevalence of PE ranges from 8-10\%, contributing to maternal (12 to $15 \%$ ) and perinatal (24\%) mortality. The incidence is more in nulliparity around $15 \%$, and in multiparas around $10 \% .^{1,2}$ The global incidence of pregnancy-induced hypertension is reported to be $3-18 \% .^{3}$ If untreated, pregnancy hypertension can progress to $\mathrm{PE}$ and eclampsia, which are life-threatening. ${ }^{4}$
PE subdivided into early onset PE with delivery <34 weeks gestation, and late onset PE with delivery $\geq 34$ weeks gestation. Early onset PE associated with higher incidence of adverse outcome..$^{5,6}$ The definitive risk factors or etiology being unknown, its prevention becomes a difficult task. Even though PE usually occurs from the late second to the third trimester, evidence of organ pathophysiology found at very early stages of pregnancy. The prediction of PE at early gestation lead to more effective prophylactic strategies. ${ }^{7}$ 
A combination of maternal risk factors, such as uterine artery pulsatility index (PI), mean arterial pressure (MAP), pregnancy-associated plasma protein-A (PAPPA), placental growth factor (PlGF), PP13, and fetal hemoglobin levels at 11-13 weeks' can be used to identify pregnancies at high risk for early-onset PE. ${ }^{8-12}$

Hence there was a need of affordable test that could permit pre-symptomatic diagnosis to identify and monitor the women for better antenatal surveillances.

The study aimed to evaluate the screening efficacy of maternal serum biomarker, and Doppler ultrasonography during the early weeks of gestation for early detection of $\mathrm{PE}$ and to take the necessary measures to prevent the progression of the condition to a severe form.

\section{METHODS}

This was a hospital-based prospective observational study conducted at Department obstetrics and gynecology department, Narayana medical college, and hospital, Nellore, over two years (October 2017 to October 2019). The study protocol approved by institutional ethical committee, Narayana Medical College and Hospital, Nellore, Andhra Pradesh.

\section{Inclusion criteria}

Primigravidae and multigravida $<13$ weeks of gestation will be recruited with normal $\mathrm{BP}$ and renal function and no evident proteinuria upon measurement with a dipstick.

\section{Exclusion criteria}

Pregnant women with history of smoking and alcoholism. Pregnant women with gestational diabetes, overt diabetes mellitus, previous history of PIH, cardiovascular disease, anemia, and multiple pregnancies. Pregnant women with chronic liver and kidney disease, chronic hypertension (HTN), chronic urinary tract infection, and other chronic diseases. Any maternal or fetal condition that requires termination of pregnancy (congenital malformations like Downs syndrome). Active vaginal bleeding.

After informed written consent, 100 numbers of pregnant women of age 18-40 years who are less than 13 weeks of gestation attending the Obstetrics department fulfilling the inclusion and exclusion criteria recruited into the study. The detailed history, clinical examination, and gestational age confirmed by ultrasonogram. Apart from routine antenatal investigations, other investigations sent related to the present study like serum Inhibin A, and Doppler USG done. All the enrolled women followed until delivery.

Blood samples were collected, and the serum inhibin A $(\mathrm{pg} / \mathrm{ml})$ estimation was done by the chemiluminescent immunometric assay (CLIA) method. Uterine artery
Doppler velocimetry was done at 11-13 weeks and 19-22 weeks of gestation by PHILIPS HD11XE transabdominal ultrasound machine using a 4-6 $\mathrm{MHz}$ probe through transabdominal method. Pulsed wave Doppler was used for obtaining three consecutive waveforms, and the pulsatility index (PI) was measured. Blood pressure was measured at each visit, and mean arterial pressure calculated at mid-trimester.

The variables that were taken in this study were maternal age, parity, BMI, MAP, SBP, DBP (last trimester), inhibin A, uterine artery PI (UAPI) in $1^{\text {st }}$ and $2^{\text {nd }}$ trimester, gestational age at delivery, mode of delivery, neonatal outcome like APGAR and birth weight.

\section{Statistics}

Mean \pm SD of all variables calculated for the preeclampsia and normotensive group; the difference was tested using the chi-square test, and some variables (inhibin A, Uterine artery PI) expressed in multiples of median (MoM). The cut-off values, sensitivity, specificity, and predictive values of inhibin A, and UAPI in the $1^{\text {st }}$ and $2^{\text {nd }}$ trimester were analysed. $\mathrm{P}$ value $<0.05$ considered as significant difference. The data obtained were analyzed using IBM SPSS software version 24.0.

\section{RESULTS}

Among 100 pregnant women, 5 pregnancies were terminated due to lethal congenital anomalies, 6 women had miscarriages, 9 members changed their place of delivery, 4 women developed gestational diabetes, 10 members withdrew their consent in subsequent visits, 2 pregnancies complicated by APH, 4 members landed in a preterm delivery and 8 members were lost follow-up and hence were excluded from the study.

Only 52 members included in the final analysis and followed until delivery. Among them, 45 women remained normotensive, and seven women developed preeclampsia. Out of 7 preeclampsia women, 5 (71.4\%) members were primigravidae, and $2(28.6 \%)$ members were multigravidae, indicating that preeclampsia was more common in primigravidae when compared to multigravidae $(\mathrm{p}=0.429)$.

The mean age among normotensive pregnant women was $24.18 \pm 4.628$ years and $23.14 \pm 3.436$ years in the preeclampsia group $(\mathrm{p}=0.574)$.

Results showed that the preeclampsia group had a significantly higher BMI than the normotensive group. The preeclampsia group had a significantly higher MAP, higher inhibin $\mathrm{A}$ in the preeclampsia group when compared to normotensive group. The mean uterine artery PI at the first trimester and second trimester was significantly higher in women who developed PE subsequently compared to normotensive group (Table 1). 
Table 1: Mean maternal risk factors in normotensive versus preeclampsia.

\begin{tabular}{|c|c|c|c|c|}
\hline Variable & $\begin{array}{l}\text { Normotensive }(\mathrm{n}=45) \\
(\text { Mean } \pm \text { SD) }\end{array}$ & $\begin{array}{l}\text { Preeclampsia }(\mathrm{n}=7) \\
(\text { Mean } \pm \text { SD })\end{array}$ & T value & P value \\
\hline Maternal age & $24.18 \pm 4.628$ & $23.14 \pm 3.436$ & 0.566 & $0.574 \mathrm{NS}$ \\
\hline Mean BMI $\left(\mathrm{kg} / \mathrm{m}^{2}\right)$ & $25.26 \pm 2.82$ & $30.9 \pm 3.15$ & -4.838 & $<0.0001 \mathrm{VHS}$ \\
\hline Mean MAP (mmHg) & $87.23 \pm 4.97$ & $105.13 \pm 5.84$ & -8.662 & $<0.0001$ VHS \\
\hline Inhibin A (MoM) & $1.03 \pm 0.488$ & $2.10 \pm 0.77$ & -4.979 & $<0.0001$ VHS \\
\hline UAPI at $1^{\text {st }}$ trimester $($ MoM $)$ & $0.96 \pm 0.19$ & $1.34 \pm 0.20$ & -4.777 & $<0.0001$ (VHS) \\
\hline Mean UAPI at $2^{\text {nd }}$ trimester $(\mathrm{MoM})$ & $0.95 \pm 0.24$ & $1.45 \pm 0.17$ & -5.210 & $<0.0001$ (VHS) \\
\hline Mean gestational age at delivery (weeks) & $39.02 \pm 0.81$ & $36.35 \pm 1.78$ & 3.901 & $0.007 \mathrm{SIG}$ \\
\hline
\end{tabular}

$\mathrm{NS}=$ not significant. VHS- Very high significant SIG- Significant

Table 2: Newborn parameters in normotensive group versus preeclampsia group.

\begin{tabular}{|c|c|c|c|c|}
\hline Variable & $\begin{array}{l}\text { Normotensive }(n=45) \\
(m e a n \pm \text { SD) }\end{array}$ & $\begin{array}{l}\text { Preeclampsia }(n=7) \\
(\text { mean } \pm \text { SD })\end{array}$ & T value & P value \\
\hline Mean birth weight (B. WT) (kg) & $3.016 \pm 0.26$ & $2.19 \pm 0.59$ & 3.580 & 0.010 (SIG) \\
\hline APGAR $1^{\text {st }}$ minute & $6.60 \pm 1.03$ & $4.71 \pm 1.38$ & 4.301 & $<0.0001 \mathrm{VHS}$ \\
\hline APGAR $5^{\text {th }}$ minute & $8.42 \pm 0.91$ & $6.71 \pm 1.38$ & 3.617 & $0.016 \mathrm{SIG}$ \\
\hline
\end{tabular}

The mean gestational age at delivery in the preeclampsia group was $36.35 \pm 1.78$ weeks, and in normotensive women was $39.02 \pm 0.81$ weeks $(\mathrm{p}=0.007)$. It indicates that the average gestational age at delivery in the preeclampsia group was significantly lower than that in the normotensive group.

Among normotensives, 26 (57.8\%) members had normal vaginal delivery, and $19(42.2 \%)$ members underwent LSCS. Out of 7 preeclampsia women, 2 (28.6\%) women delivered vaginally, and $5(71.4 \%)$ members had LSCS. It shows there was no significant difference between the preeclampsia group and normotensive pregnant women concerning the mode of delivery $(\mathrm{p}=0.149)$.

The average newborn birth weight in the preeclampsia group was significantly lower than that in the normotensive group and the APGAR at $1^{\text {st }}$ and $5^{\text {th }}$ minute was lower in the preeclampsia group when compared to the normotensive group with significant $\mathrm{p}$ value $<0.0001$ and 0.016 (Table 2)

Table 3: Early onset versus late onset PEprimigravida versus multigravida.

\begin{tabular}{|lll|}
\hline Parity & Early onset PE & Late onset PE \\
\hline \multirow{2}{*}{ Primi } & 3 & 2 \\
\cline { 2 - 3 } & $75 \%$ & $66.7 \%$ \\
\hline \multirow{2}{*}{ Multi } & 1 & 1 \\
\cline { 2 - 3 } & $25 \%$ & $33.3 \%$ \\
\hline
\end{tabular}

Chi-square value $=0.674, \mathrm{P}$ value $=0.7147$ (not significant $)$

$75 \%$ of primigravida and $25 \%$ of multigravida had early onset preeclampsia and corresponding figures of late onset preeclampsia were $66.7 \%$ and $33.3 \%$ respectively. It indicates there was no statistically significant difference between the onset of preeclampsia in primigravidae and multigravidae ( $\mathrm{p}$ value-0.714).

The MAP in primigravidae was $90.78 \pm 8.77 \mathrm{mmHg}$ and in multigravidae was $88.07 \pm 6.58 \mathrm{mmHg}$, indicates that there was no statistically significant difference in MAP ( $p$ value 0.229 ).

The mean inhibin A in primigravidae was $1.30 \pm 0.69$ and in multigravidae was $1.00 \pm 0.52$, which indicates that there was no significant difference in inhibin levels ( $p$ value 0.099).

The first-trimester uterine artery PI in primigravidae was $0.98 \pm 0.22 \mathrm{MoM}$ and in multigravidae was $1.04 \pm 0.30$ MoM, which indicates that there was no significant difference in first-trimester uterine artery PI between primigravidae and multigravidae with ( $p$ value- 0.405 ) and the corresponding figures in second-trimester uterine artery PI were 1.01 $\pm 0.30 \mathrm{MoM}$ and $1.02 \pm 0.28 \mathrm{MoM}$ respectively, which indicates that there was no statistically significant difference in second-trimester uterine artery PI between primigravidae and multigravidae with $\mathrm{p}$ value- 0.953 .

Table 5: Cut off value, sensitivity, specificity, positive predictive value (PPV), and negative predictive value (NPV) of markers.

\begin{tabular}{|llll|}
\hline Variables & Inhibin A & $\begin{array}{l}\text { UAPI at } \\
\text { 1 }^{\text {st }} \text { TRI }\end{array}$ & $\begin{array}{l}\text { UAPI at } \\
\text { 2 }^{\text {nd }} \text { TRI }\end{array}$ \\
\hline Cut-off value & $>1.47$ & $>1.13$ & $>1.20$ \\
\hline Sensitivity (\%) & 71.43 & 71.43 & 100.00 \\
\hline Specificity (\%) & 95.56 & 95.56 & 84.44 \\
\hline PPV (\%) & 62.5 & 71.43 & 50.00 \\
\hline NPV (\%) & 95.45 & 95.56 & 100.00 \\
\hline
\end{tabular}


The cut-off value of maternal serum inhibin A for prediction of preeclampsia was $1.47 \mathrm{MoM}$. The value in our study $2.10 \pm 0.77$ ( $\mathrm{p}$ value $<0.0001 \mathrm{VHS}$ ) which had a sensitivity of $71 \%$, the specificity of $95 \%$, PPV of $62.5 \%$, and NPV of $95 \%$.

The cut-off values of first-trimester uterine artery Doppler PI to predict the preeclampsia was $>1.13$ MoM. The value in our study $1.3 \pm 0.20$ ( $\mathrm{p}$ value $<0.0001$ (VHS) which had a sensitivity of $71 \%$, the specificity of $95 \%$, PPV of $71 \%$ and NPV of $95 \%$.

The cut-off values for uterine artery Doppler PI in the second trimester to predict preeclampsia was $>1.20$ MoM. The value in our study was $1.45 \pm 0.17 \mathrm{MoM}(\mathrm{p}$ value $<0.0001$ ) which had a sensitivity of $100 \%$, the specificity of $84 \%$, PPV of $50 \%$ and NPV of $100 \%$.

\section{DISCUSSION}

The definitive pathophysiology of preeclampsia is not known. There is proof that increased proliferation of the underlying cytotrophoblast in preeclampsia, may be due to the repair of the ischemic damage to the surface syncytiotrophoblast. These changing processes of damage and repair may cause functional alteration of the surface layer of syncytiotrophoblast in the PE placenta, and this may explain the increased levels of certain biophysical and biochemical markers.

The incidence of PE worldwide ranges from $5-7 \%$ of pregnancies, and in India, the prevalence ranges from 8$10 \%$. In the present study, out of 52 pregnant women, seven members developed preeclampsia subsequently with the incidence of $13.4 \% .^{12-16}$

Maternal age is one of the most common risk factor associated with pregnancy-related hypertensive disorders. Young women of less than 20 years and women over 35 years are found to be more prone for the development of Preeclampsia. ${ }^{17-19}$

$\mathrm{PE}$ is twice as common in primigravida women as compared to multigravida. The present study shows increased incidence of $\mathrm{PE}$ in primigravidae when compared to multigravidae in par with the studies done by Poon et al, and Akolekar et al, showing that the incidence of preeclampsia are significantly more in primigravidae. ${ }^{20,21}$ whereas a study done by Sharma et al shows the incidence of PE was more in multigravidae. ${ }^{22}$

The risk of preeclampsia was more in obese patients, and the risk doubles with each 5 to $7 \mathrm{~kg} / \mathrm{m}^{2}$ increase in prepregnancy BMI. Obesity is associated with renal hyperfiltration, hyperperfusion, glomerular hypertrophy and diabetes-like changes including focal mesangial sclerosis or glomerular and tubular basement membrane thickening. ${ }^{13,14,23}$ In our study also preeclampsia was noted in women with high BMI $\left(30 \mathrm{~kg} / \mathrm{m}^{2}\right)$.
In PE, the possible mechanism for the disturbed invasion is hardening and structural abnormality of the vessel wall. Hardening of blood vessel walls might be provoked by persistent high blood pressure. In pregnancies that develop PE, MAP at 22-24 weeks gestation is higher than the normal pregnancies, and the increase is inversely related to the gestational age at delivery. ${ }^{24,25}$ Studies done by Gallo et al, and Jaldli et al, show the midtrimester MAP was significantly higher in the preeclampsia group when compared to the normotensive group and the present study is in accord with the above studies with significant $\mathrm{p}$ value $<0.001$.

The increased maternal concentration of the placental products in $\mathrm{PE}$ is due to the consequence of impaired placentation leading to placental damage and subsequent spillage into the maternal circulation. Alternatively, impaired placental perfusion and placental damage followed by a regenerating process causing the increased synthesis of inhibin A. As per the studies of Spencer et al, Sebire et al, Cuckle et al, the inhibin A concentration was significantly higher in preeclampsia group. ${ }^{5,9}$ This study has proved that the levels of inhibin $\mathrm{A}$ increased in women who developed preeclampsia than who did not develop PE subsequently. In the present study, the sensitivity of inhibin A was $71 \%$, and specificity was $95 \%$, indicating that the estimation of inhibin $\mathrm{A}$ in the first trimester seems to be a specific marker for early prediction of PE. ${ }^{17}$

In pregnancies destined to develop $\mathrm{PE}$ have raised placental vascular resistance, which is detected in uterine artery Doppler ultrasound in the form of increased pulsatility index. In the studies done by Narang et al, uterine artery PI at 11-14 weeks of gestation found to be the best parameter for screening women prone for developing PE. ${ }^{14}$ Our study also has shown high values in both first trimester and second trimester mean uterine artery PI in the preeclampsia group when compared to normotensives with high sensitivity and specificity along with significant $p$ value. On the whole second trimester uterine artery PI seems to be a more sensible marker for the prediction of PE in early onset PE (100\% sensitivity).

Early-onset PE (also known as "placental PE") results from impaired trophoblast invasion into the spiral arteries, leading to placental ischemia and oxidative stress. Placental histology in early-onset PE demonstrates thrombotic changes in the villous tree. Late-onset PE ("maternal PE") is considered to be secondary to the maternal cardiovascular and metabolic predisposition for endothelial dysfunction. Study done by Narang et al shows that $11.54 \%$ of pregnant women developed PE. Among them, 7.69\% developed early-onset PE, and $3.85 \%$ developed late-onset PE. ${ }^{14}$ The present study shows consistent findings in par with the above study, 7.7\% developed early-onset PE and 5.8\% developed late onset PE with significant $p$ value. 
Delivery is the definitive management of preeclampsia depending upon its severity. The mean gestational age at delivery is significantly lower in the preeclampsia group when compared to the normotensive group. A positive correlation found between neonatal birth weight and the time of development of PE. There is a difference between near-term PE (late onset preeclampsia) without demonstrable fetal involvement and early onset PE associated with low birth weight and preterm delivery. In severe PE before 34 weeks, fetus is usually growth restricted and induction of labour is invariably being unsuccessful, leading to a high probability of operative delivery. Gupta et al showed the cesarean section rate is significantly higher in the preeclampsia group when compared to the normotensive group ( $p$ value 0.001$){ }^{26}$ But as per Zadeh et al, there was no significant difference observed in type of delivery between preeclampsia and normotensive groups. ${ }^{18}$ Our study findings found to be consistent with Zadeh et al study showing no statistically significant difference between 2 groups $(\mathrm{p}=0.149) .{ }^{18}$

As per our study figures, serum inhibin with a cut off value of $>1.47$, preeclampsia developed in $10 \%$ of primigravidae and none of the multigravidae.

At a cut-off value $>1.13$ of UAPI in first trimester, $3.3 \%$ of the primigravidae and $4.5 \%$ of multigravidae developed PE. At a cut-off value $>1.20$ of uterine artery PI in second trimester, $16.6 \%$ of the primigravidae and $9.09 \%$ of multigravidae developed PE. Second trimester uterine artery PI is appears to be sensitive marker.

In the present study, we did a step further by considering the cut-off value to various markers and to find out whether markers influence the parity for the development of PE. With the same cut-off values the incidence of PE in primigravidae is higher when compared to the multigravidae. So, this raises a point to detect the factors which are preventing PE in multigravidae. A search for those protecting factors in the multigravidae which might be helpful in the future to mark the presence/absence of the same in a primigravidae to pin-point her future vulnerability to the development of PE.

Limitations of this study are it consists of smaller sample size, and it's a single centre study.

\section{CONCLUSION}

Prediction of PE remains a challenge even after the identification of a large number of putative biomarkers to predict the pathology and its onset. The present study concluded to a reasonable extent that the women who are prone to develop PE subsequently, had high levels of MAP, UAPI ( $1^{\text {st }}$ and $2^{\text {nd }}$ trimester $)$, inhibin A than in the normotensive women. In our setting, MAP, UAPI, inhibin A markers appeared to be better screening modalities for prediction of preeclampsia.
Conflict of interest: None declared

Ethical approval: The study was approved by the Institutional Ethics Committee Narayana Medical College, Nellore

\section{REFERENCES}

1. Callen PW. The role of Doppler ultrasound in obstetrics. In: Ultrasonography in Obstetrics and Gynaecology. 5th edn. Elsevier Saunders publication; 2008:794-807.

2. Guzman ER, Kontopoulos E, Zalud I. Doppler velocimetry of the utero placental circulation. In: Doppler Ultrasound in Obstetrics and Gynecology. 2nd edn. Springer publication; 2005:227-254.

3. Duley L. The global impact of pre-eclampsia and eclampsia. Semin Perinatol. 2009;33(3):130-7.

4. Sharma K, Singh R, Kumar M, Gupta U, Rohil V, Bhattacharjee J. First-trimester inflammatory markers for risk evaluation of pregnancy hypertension. J Obstet Gynecol India. 2018;68(1):2732.

5. Spencer-Jones J. Make every mother and child count. S Afr Med. 2005;95:382.

6. Bowyer L. The Confidential Enquiry into Maternal and Child Health (CEMACH). Saving Mothers' Lives: reviewing maternal deaths to make motherhood safer 2003-2005. The Seventh Report of the Confidential Enquiries into Maternal Deaths in the UK. Obstetric Medicine. 2008 Sep;1(1):54.

7. Thilaganathan B, Wormald B, Zanardini C, Sheldon J, Ralph E, Papageorghiou AT. Early-pregnancy multiple serum markers and second-trimester uterine artery Doppler in predicting pre-eclampsia. Obstet Gynecol. 2010;115:1233-8.

8. Akolekar R, Syngelaki A, Beta J, Kocylowski R, Nicolaides KH. Maternal serum placental protein 13 at 11-13 weeks of gestation in pre-eclampsia. Prenat Diagn. 2009;29:1103-8.

9. Cuckle HS. Screening for pre-eclampsia- lessons from aneuploidy screening. Placenta. 2011;32(Suppl.1):S42-8.

10. Nicolaides KH, Bindra R, Turan OM, Chefetz I, Sammar M, Meiri H, et al. A novel approach to firsttrimester screening for early pre-eclampsia combining serum PP-13 and Doppler ultrasound. Ultrasound Obstet Gynecol. 2006;27:13-7.

11. Gram M, Anderson UD, Johansson ME, EdströmHägerwall A, Larsson I, Jälmby M, et al. The human endogenous protection system against cell-free hemoglobin and heme is overwhelmed in preeclampsia and provides potential biomarkers and clinical indicators. PLoS One. 2015;10(9):e0138111.

12. Anderson UD, Gram M, Thilaganathan B, Åkerström B, Hansson SR. [97-POS]: Free fetal hemoglobin and hemoglobin-scavenging proteins are predictive first and second trimester biochemical markers for preeclampsia. Pregnanc Hypertens. 2015;5(1):53. 
13. Fatema K, Khatun M, Akter S, Ali L. Role of urinary albumin in the prediction of preeclampsia. Faridpur Med Coll J. 2011;6(1):14-8.

14. Narang S, Agarwal A, Das V, Pandey A, Agrawal S, Ali w, et al. Prediction of pre-eclampsia at 11-14 weeks of pregnancy using mean arterial pressure, uterine artery Doppler and pregnancy-associated plasma protein-A. Int $\mathbf{J}$ Reprod Contracept Obstet Gynecol. 2016;5(11):3948-53.

15. Ritukamra HD, Gupta KD, Natu SM. Role of Urinary calcium/creatinine ratio prediction of PIH. J Obset Gynecol India. 1997;47(4).

16. Rodriguez MH, Masaki DI, Mestman J, Kumar D, Rude R. Calcium/creatinine ratio and microalbuminuria in the prediction of pre-eclampsia. Am J Obstet Gynecol. 1988;159:1452-5.

17. El-Gharib MN, Morad. M Maternal serum inhibin-A for predicting preeclampsia. J Matern Fet Neonat Med. 2011;24(4):595-9.

18. Moslemi Zadeh N, Naghshvar F, Peyvandi S, Gheshlaghi P, Ehetshami S. PP13 and PAPP-A in the first and second trimesters: predictive factors for preeclampsia?. Int Schol Res Notice. 2012;2012.

19. Yu N, Cui H, Chen X, Chang Y. First trimester maternal serum analytes and second trimester uterine artery Doppler in the prediction of preeclampsia and fetal growth restriction. Taiwan J Obstet Gynecol. 2017;56(3):358-61.

20. Poon L, Kametas N, Bonino S, Vercellotti E, Nicolaides $\mathrm{K}$. Urine albumin concentration and albumin-to-creatinine ratio at $11+0$ to $13+6$ weeks in the prediction of pre-eclampsia. BJOG. 2008;115:866-73.
21. Akolekar R, Syngelaki A, Sarquis R, Zvanca M, Nicolaides KH. Prediction of early, intermediate and late pre-eclampsia from maternal factors, biophysical and biochemical markers at 11-13 weeks. Prenat Diagn. 2011;31(1):66-74.

22. Sharma K, Singh R, Kumar M, Gupta U, Rohil V, Bhattacharjee J. First-trimester inflammatory markers for risk evaluation of pregnancy hypertension. J Obstet Gynecol India. 2018;68(1):2732.

23. Salomon LJ, Benattar C, Audibert F, Fernandez H, Duyme M, Taieb J, et al. Severe preeclampsia is associated with high inhibin A levels and normal leptin levels at 7 to 13 weeks into pregnancy. Am J Obstet Gynecol. 2003;189:1517-22.

24. Gallo D, Poon LC, Fernandez M, Wright D, Nicolaides KH. Prediction of preeclampsia by mean arterial pressure at 11-13 and 20-24 weeks' gestation. Fet Diagn Therap. 2014;36(1):28-37.

25. Jadli A, Ghosh K, Damania K, Satoskar P, Bansal V, Shetty S. Prediction of preeclampsia using combination of biomarkers at 18-23 weeks of gestation: A nested case-control study. Pregnanc Hypertens. 2019;17:20-7.

26. Gupta N, Gupta T, Asthana D. Prediction of preeclampsia in early pregnancy by estimating the spot urinary albumin/creatinine ratio. J Obstet Gynecol India. 2017;67(4):258-62.

Cite this article as: Hymavathi K, Davuluru SR, Shaik S, Kaviti S. Potential screening strategies for early prediction of pre-eclampsia. Int J Reprod Contracept Obstet Gynecol 2021;10:1436-41. 